\title{
Saturated steam process with direct steam generating parabolic troughs
}

\author{
M. Eck ${ }^{\mathrm{a}, *}$, E. Zarza ${ }^{\mathrm{b}}$ \\ ${ }^{a}$ DLR, Institute of Technical Thermodynamics, Pfaffenwaldring 38-40, 70569 Stuttgart, Germany \\ ${ }^{\mathrm{b}}$ CIEMAT, Plataforma Solar de Almería (PSA), P.O. Box 22, 04200 Tabernas (Almería), Spain
}

Received 15 November 2004; received in revised form 14 March 2006; accepted 24 March 2006

Available online 12 May 2006

Communicated by: Associate Editor Klaus Vajen

\begin{abstract}
The direct steam generation (DSG) in parabolic trough collectors is an attractive option regarding the economic improvement of parabolic trough technology for solar thermal electricity generation in the multi Megawatt range. The European DISS project has proven the feasibility of the direct steam generation under real solar conditions in more than 4000 operation hours. Within the European R\&D project INDITEP the detailed engineering for a pre-commercial DSG solar thermal power plant with an electrical power of $5 \mathrm{MW}$ is being performed. This small capacity was chosen to minimise the risk for potential investors.

In regards to DSG solar thermal power plants, only steam cycles using superheated steam have been investigated so far. The paper will investigate the advantages, disadvantages, and design considerations of a steam cycle operated with saturated steam for the first time. For near term applications, saturated steam operated DSG plants might be an interesting alternative for power generation in the small capacity range due to some specific advantages:
\end{abstract}

- Simple set up of the collector field.

- Proven safe collector field operation.

- Higher thermal efficiency in the collector field.

(C) 2006 Elsevier Ltd. All rights reserved.

Keywords: Solar thermal power plants; Direct steam generation; Parabolic trough; Saturated steam; System analysis

\section{Introduction}

Solar thermal power plants are an attractive option for the electricity production from renewable

\footnotetext{
* Corresponding author. Fax: +49 7116862747

E-mail address: markus.eck@dlr.de (M. Eck).
}

energy sources. A new feed in law in Spain (Ragwitz and Huber, 2005) has led to the development of several solar thermal power plant projects. To reduce the risk for the investors proven and reliable technologies are preferred. Additionally the choice of small power plants may lead to a further risk reduction. These considerations have led to the 
development of the so-called PS-10 project, a solar tower producing saturated steam (Osuna et al., 2004) and the INDITEP project (Zarza et al., 2004), a parabolic trough power plant with a net capacity of $5 \mathrm{MW}$ using direct steam generation (DSG). The INDITEP plant serves as a reference in this paper. This reference plant is compared to a second option where saturated steam is produced in the collector field. This saturated steam option may lead to a further simplification of the system and thus increases its reliability.

During operation of the life size DISS test facility at the Plataforma Solar de Almería (PSA), the so called recirculation mode has proven to be advantageous for near term applications due to its safe operation of the collector field (Eck et al., 2003). Accordingly both collector fields are operated in recirculation mode.

The two options are investigated by means of yearly energy analysis for a specific site in Spain. Special attention is paid to the part-load characteristic of both options and the influence of different operation modes of the power block. Furthermore the necessary investment and O\&M issues are considered.

\section{Basic assumptions}

Within the INDITEP project, the detailed engineering and design for the first DSG solar thermal power plant was performed for a size of $5 \mathrm{MW}$ located near Seville, Spain (latitude: $37^{\circ} 24^{\prime}$ N; longitude: $5^{\circ} 58^{\prime} \mathrm{W}$ ) (Zarza et al., 2004). Due to economics of scale, the plant size was not chosen for cost-effective power generation. However, the size was selected to minimize the financial risks associated with large initial capital investments for potential investors.

Since the plant only produces a rated $5 \mathrm{MW}$ of power, the steam turbine design, with a specified minimum outlet steam quality of 0.85 , was limited to only a single extraction line. The extraction line, or bleed stream, is used for dearation in a feed water tank operated at 5.6 bar. The basic boundary conditions are summarised in Table 1.

A dry cooling condenser is considered. Due to the high ambient temperature at the site in summertime, a condensation pressure of 0.1 bar was considered for the design point (June 21st) with a resulting condensation temperature of $45.8^{\circ} \mathrm{C}$. Dry cooling is chosen for the power plants because water is often not available for cooling purposes at potential sites in Spain.
Table 1

Basic boundary conditions for design point

\begin{tabular}{ll}
\hline$p_{\text {cond }}$ & $0.1 \mathrm{bar}$ \\
$p_{\text {dear }}$ & $5.6 \mathrm{bar}$ \\
$p_{\max }$ & $65 \mathrm{bar}$ \\
$T_{\max }$ & $400^{\circ} \mathrm{C}$ \\
$P_{\text {el }}$ & $5 \mathrm{MW}$ \\
$x_{\min }$ & 0.85 \\
\hline
\end{tabular}

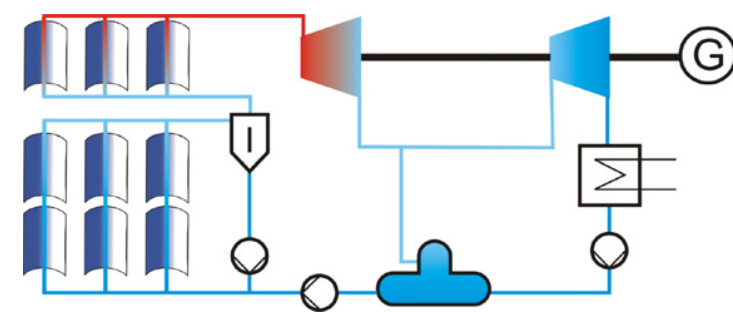

Fig. 1. Schematic diagram of the superheated steam cycle.

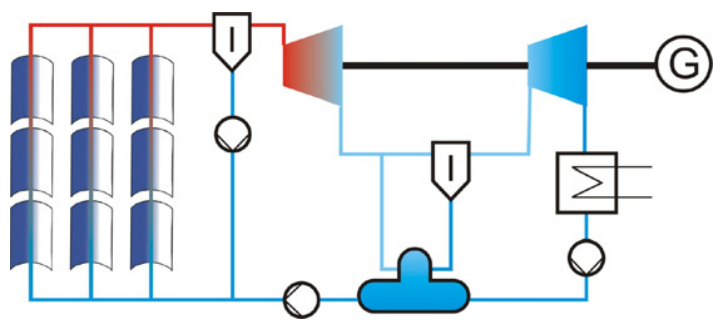

Fig. 2. Schematic diagram of the saturated steam cycle.

The schematic diagram of a simple steam cycle operated with superheated steam and in recirculation mode is shown in Fig. 1. In this paper this basic operation mode of using superheated steam is compared to a DSG plant operated with saturated steam. A schematic diagram of a saturated steam cycle is displayed in Fig. 2.

In Fig. 2 the collector field is also operated in recirculation mode. The saturated steam leaving the field separator is fed directly to the saturated steam turbine. Again there is a single extraction line for dearation. In this case the steam re-entering the second stage of the turbine has to be dried in a second separator to guarantee the minimum steam quality at the outlet of the second stage. The saturated water at the outlet of the second separator is fed to the feed-water-tank.

\section{The site}

The performance of the system strongly depends on the site chosen. The performance analysis in this 
study is conducted for a site close to Seville (Spain) using hourly ambient temperature and the direct normal irradiation (DNI) data collected via satellite. The yearly sum of the DNI for the site is $2012 \mathrm{kWh} /$ $\mathrm{m}^{2}$. Figs. 3 and 4 show the distribution of the mean monthly DNI in $\mathrm{W} / \mathrm{m}^{2}$ and ambient temperature in Celsius, respectively. Since a dry cooling condenser was chosen for the power plant, the ambient temperature affects the condenser temperature and thus its efficiency. Therefore, the power block efficiency will decrease in summer due to higher ambient temperatures.

The parabolic troughs used for the power plant cannot utilize all of the available DNI due to single axis tracking. Thus, the total available DNI is multiplied by the cosine of the incident angle to determine the useful DNI available for absorption by the collector. Fig. 5 displays the corrected DNI sorted according to the number of hours they occur. For simulation purposes, it is assumed that the power plant only operates at a corrected DNI greater than $250 \mathrm{~W} / \mathrm{m}^{2}$. Plants operating at DNI values lower than $250 \mathrm{~W} / \mathrm{m}^{2}$ are not profitable due to thermal losses in the solar field and high

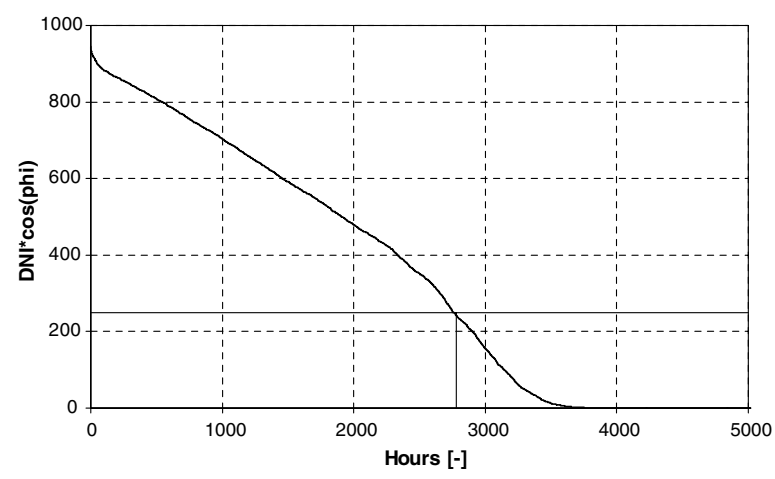

Fig. 5. Corrected DNI sorted according to the number of hours.

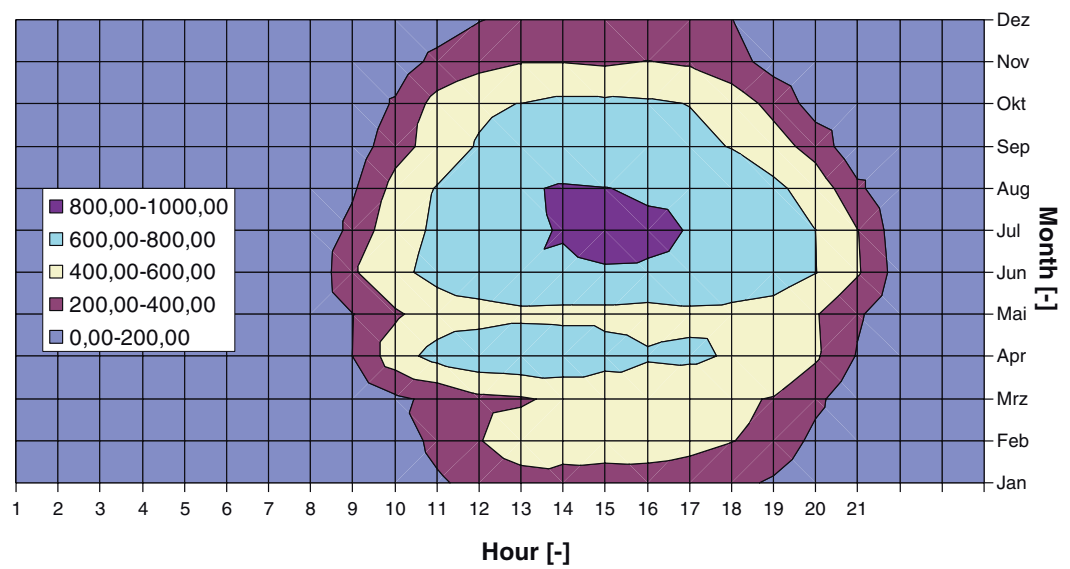

Fig. 3. Distribution of the mean monthly DNI for the site at Seville (Spain, in $\mathrm{W} / \mathrm{m}^{2}$ ).

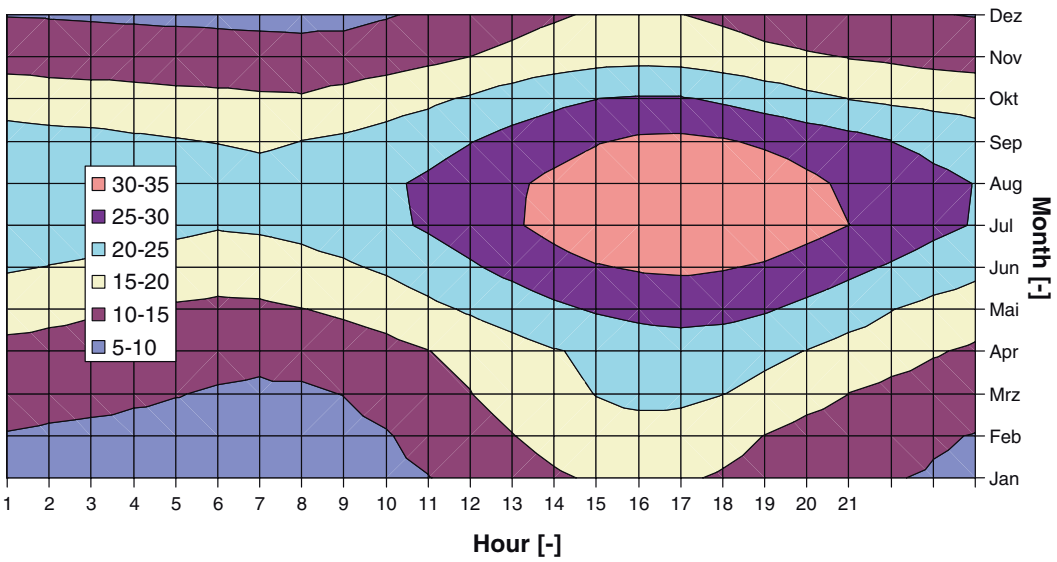

Fig. 4. Mean monthly ambient temperature for Seville (Spain, in ${ }^{\circ} \mathrm{C}$ ). 
parasitic losses in the whole plant. According to Fig. 5, the $250 \mathrm{~W} / \mathrm{m}^{2}$ threshold is exceeded for $2770 \mathrm{~h}$ per year. Thus the useful solar energy is reduced to $1726 \mathrm{kWh} / \mathrm{m}^{2}$ a as compared to the original $2012 \mathrm{kWh} / \mathrm{m}^{2}$ a of DNI available.

\section{Thermodynamic analysis of the power plant}

For the thermodynamic analysis of the steam cycle, the commercial simulation program IPSEpro ${ }^{\circledR}$ is used. IPSEpro ${ }^{\circledR}$ has a model library containing all components necessary for the simulation of a conventional power plant. This library has been extended by DLR by all relevant solar components.

\subsection{Conceptual design of the power plants}

Collector fields for the superheated steam driven power cycle and the saturated steam cycle are presented and investigated below. The design calculations are performed for the chosen site for the 21 st of June at noon with a direct normal irradiation of $850 \mathrm{~W} / \mathrm{m}^{2}$.

\subsubsection{Power plant with superheated steam}

The schematic diagram of the power plant with superheated steam is displayed in Fig. 6 with seven collector loops connected in parallel. Due to the symmetry of the collector field, only four loops are displayed and calculated. The total mass flux is obtained by using a multiplicative factor of 1.75 . The collector field is operated in recirculation mode. In the superheating section there are two collectors connected in series, while in the evaporation section, eight collectors are connected in series. The two sections are subdivided by a separation drum. One injection nozzle per superheater row is used to control the outlet temperature of each loop. A fraction of the feed water is fed in front of the recirculation pump in order to cool down the recirculated water to avoid cavitation. The mass flux feed in front of the recirculation pump is controlled to maintain a temperature at approximately $30 \mathrm{~K}$ below the according saturation temperature. The steam quality at the separator inlet is set to 0.85 , which is enough to guarantee a sufficient cooling of the absorber tubes during steady state operation. During cloudy periods where frequent transients are expected, the steam quality should be significantly lower. The steam temperature at the turbine inlet (not displayed in Fig. 6) is set to $400{ }^{\circ} \mathrm{C}$. The mechanical efficiency of all pumps is set to 0.97 and the pump efficiency to 0.62 . The electrical and mechanical efficiency of all driving motors is set to

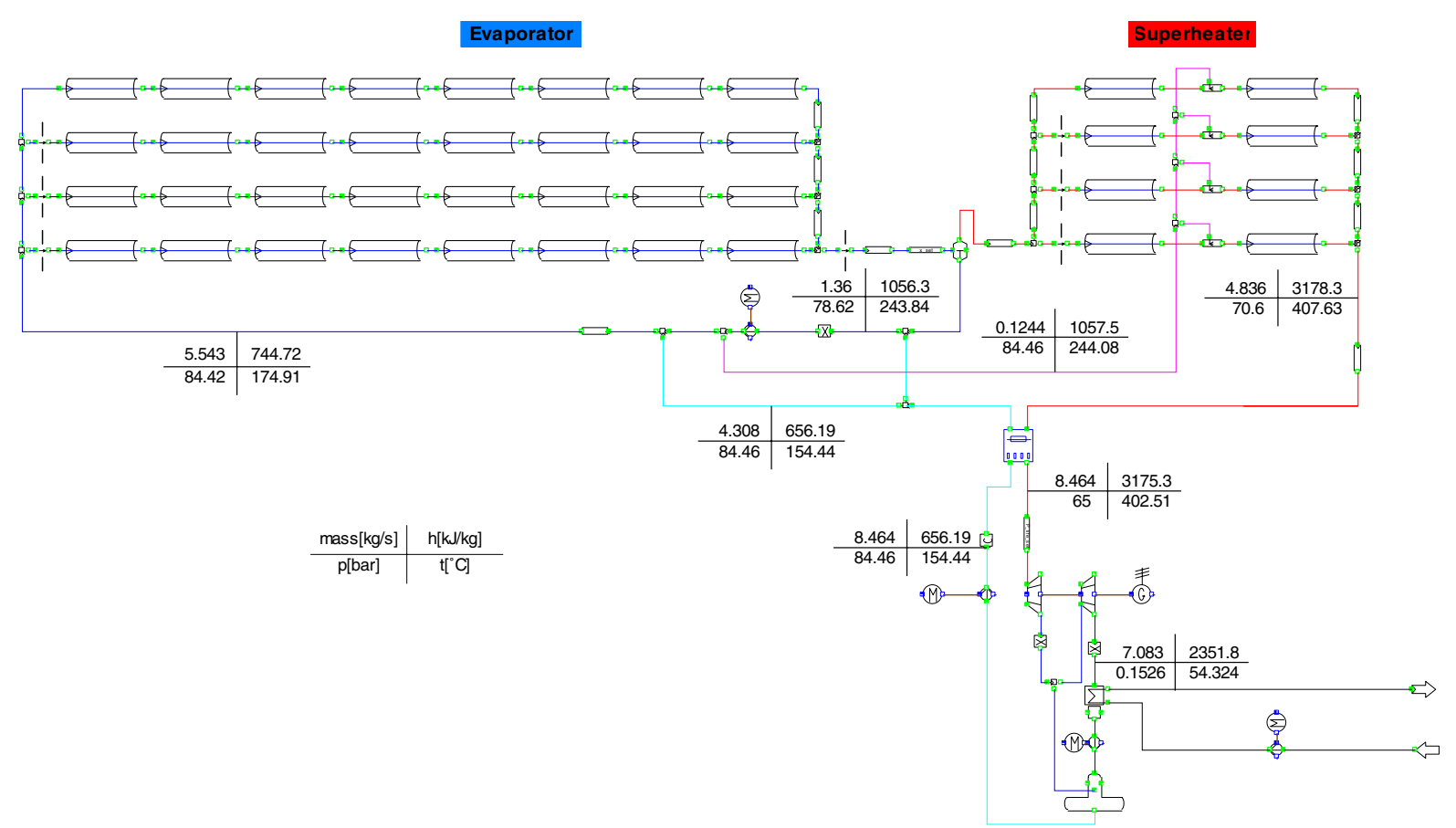

Fig. 6. Simulation set-up of the superheated steam driven solar thermal power plant. 
0.98. The isentropic efficiency of the high pressure turbine stage is 0.71 and that of the low pressure stage is 0.78 . The generator efficiency is 0.96 .

\subsubsection{Power plant with saturated steam}

The schematic diagram of the saturated steam power plant is displayed in Fig. 7. In this case nine parallel collector loops with eight collectors in series are needed. Again due to the symmetry of the collector field only five loops are displayed and calculated. In the end the mass flux is multiplied by the factor 1.8 .

The outlets of the parallel rows collectors are connected to a main header entering a separator drum. Again the steam quality at the separator inlet is set to 0.85 . The saturated water from the separator is recirculated to the collector inlet whereas the saturated steam is fed to the steam turbine. For the simulation the same component efficiencies have been used as for the superheated steam process.

\subsection{Design condition}

The design calculations are performed for both options for the specified site for the 21 st of June at noon and a DNI of $850 \mathrm{~W} / \mathrm{m}^{2}$. The incidence angle for that time and site is $14^{\circ}$. The most important design efficiencies for the two investigated options are listed in Table 2.

The thermal efficiency of the solar field is the thermal output of the solar field divided by the DNI on its total aperture area. In case of the satu-

Table 2

Design performance of the saturated and superheated steam processes

\begin{tabular}{lll}
\hline & $\begin{array}{l}\text { Superheated } \\
\text { steam }\end{array}$ & $\begin{array}{l}\text { Saturated } \\
\text { steam }\end{array}$ \\
\hline Solar field efficiency [\%] & 65.1 & 66.9 \\
Power block net efficiency [\%] & 25.9 & 24.9 \\
Total net efficiency [\%] & 16.4 & 16.2 \\
\hline
\end{tabular}

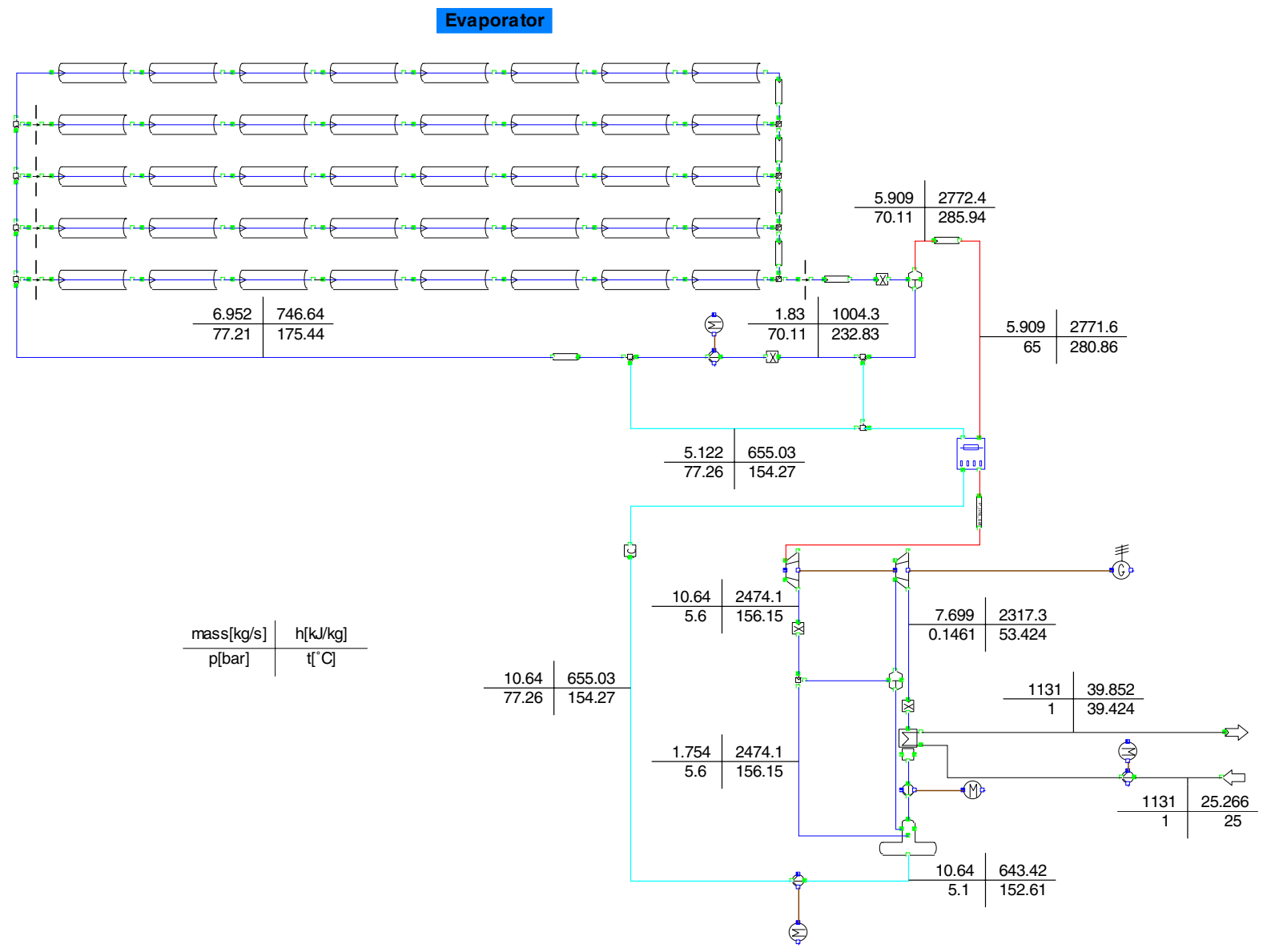

Fig. 7. Simulation set-up of the saturated steam driven solar thermal power plant. 
rated steam process the highest fluid temperature in the collector field is the saturation temperature $\left(285^{\circ} \mathrm{C}\right.$ at 70 bar). Since the collectors of the superheating section of the superheated steam process are operated at temperatures above the saturation temperature the thermal losses of the superheated steam collector field are higher. Accordingly the efficiency of the saturated steam collector field is $1.8 \%$ higher.

The second row displays the net efficiency of the power block that is defined as the net electrical output of the power plant divided by the thermal output of the solar field. Due to the higher life steam parameters of the superheated steam process the net efficiency of the power block is $1 \%$ higher. The low values of the power block efficiencies are mainly caused by their simplicity. Finally, the net efficiency of the superheated steam power plant is $0.2 \%$ higher when compared to the saturated steam process. For a final assessment of both options, their part-load performance will be investigated in the next section.

\subsection{Part-load performance of the solar thermal power plant}

Since the solar thermal power plant will operate in part-load during most times of the year, the knowledge of the part-load behaviour is crucial. In a first step, the system performance is calculated as a function of the load to obtain an impression of the part-load behaviour of each option. To assess the performance of both options at the site specified, a yearly calculation using the according meteorological data is performed.

The system performance strongly depends on the operation mode of the solar thermal power plant. For the following comparison three different operation modes are considered: fixed pressure, sliding pressure and modified sliding pressure mode.

In case of the fixed pressure mode, the operation pressure is 65 bar for all mass fluxes lower than the design mass flux. For mass fluxes higher than the design mass flux, the operation pressure is increased appropriately. In sliding pressure mode, the operation pressure is a direct function of the load and thus of the mass flux. A third option is the modified sliding pressure mode. Here the operation pressure is also a function of the load but it is always higher than 30 bar. This pressure limit of 30 bar is chosen since so far the DISS test facility has only been operated at an operation pressure higher than 30 bar. No reliable operation experience is available for an operation pressure lower than 30 bar.

It is assumed that the inlet temperature difference at the air cooled condenser is $28 \mathrm{~K}$ and the outlet temperature difference $14 \mathrm{~K}$. For the first part-load calculation, the ambient temperature is set to $25^{\circ} \mathrm{C}$.

\subsubsection{Part-load calculation}

Fig. 8 displays the efficiency of the collector field as a function of the corrected DNI. The solar field efficiency for the saturated steam option (solid lines) is always higher than that of the superheated steam

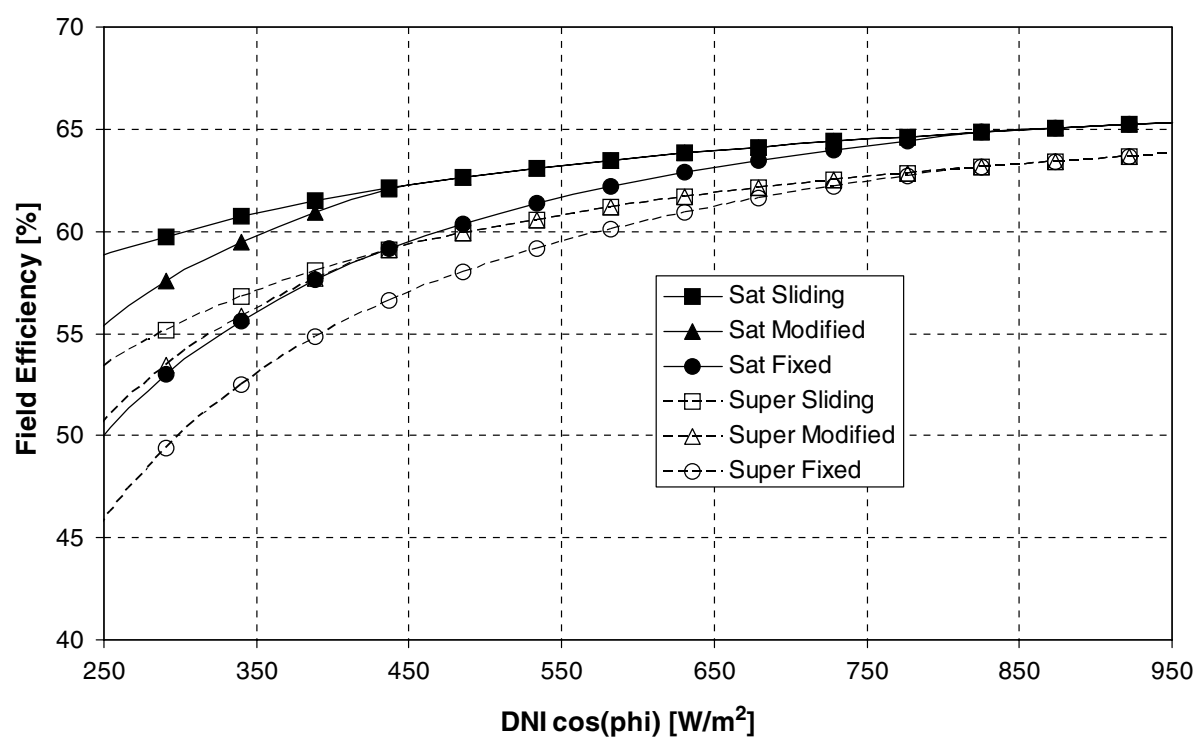

Fig. 8. Efficiency of the collector field as a function of the usable direct normal irradiation for the saturated steam and superheated steam power plant for different operation modes (sliding pressure, modified sliding pressure and fixed pressure mode). 
option. As described above, this is the result of the lower fluid temperature in the solar field and the according lower thermal losses.

Comparing the efficiency characteristic of the different operation modes for a given process option, the sliding pressure mode has the superior part-load performance followed by the modified sliding pressure and the fixed pressure mode. In the case of the fixed pressure mode, the operation pressure and, thus, the operation temperature of the evaporation section are fixed. Whereas when using one of the other modes, the pressure, the temperature and the according thermal losses decrease. The efficiency of the sliding pressure and the modified sliding pressure mode are identical as long as the operation pressure of the modified sliding pressure mode is higher than 30 bar. For a lower irradiation the pressure and thus the operation temperature will remain at this level, and accordingly, the efficiency will fall below that of the sliding pressure mode.

The efficiency characteristic of the power block is displayed in Fig. 9 for both options. As explained above, the efficiency of the superheated steam option is higher than that of the saturated steam option, and the sliding pressure mode is superior to the other operation modes. The lower efficiency of the fixed pressure and the modified sliding pressure modes is caused by the throttling losses in the first turbine stage. Finally Fig. 10 displays the effi- ciency characteristics for the complete solar thermal power plants.

\subsubsection{Yearly calculation}

For the final assessment of the system performance a yearly calculation of the power plant is performed using the satellite data for the DNI and the ambient temperature described in a previous section. As described above it is assumed that the plant is only operated for a DNI multiplied by the cosine of the incident angle higher than $250 \mathrm{~W} / \mathrm{m}^{2}$, lower values are neglected. This threshold is reached for $2770 \mathrm{~h}$ per year. The performance calculation is performed using IPSEpro. As an example Fig. 11 displays the results for the gross and net efficiency for each hour of the year for the saturated steam option operated in fixed pressure mode.

This calculation has been performed for both process options for the three different operation modes. From the results presented in Fig. 11, the peak and mean net efficiencies, the net electricity production and the equivalent full load hours have been derived. The results are presented in Table 3.

According to Table 3 the net electricity production of the saturated steam option for the specified site is approximately $4 \%$ higher for all operation modes. Although the absolute values given in Table 3 have to be regarded as preliminary, it turns out

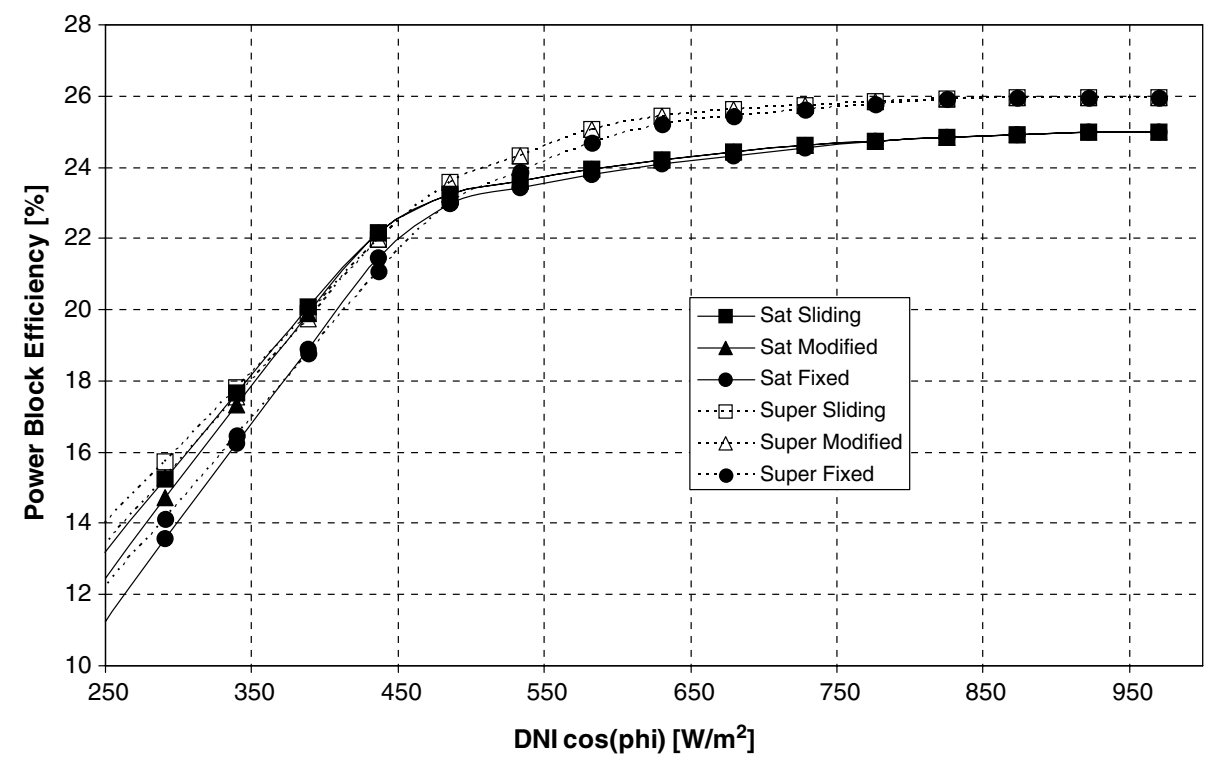

Fig. 9. Net efficiency of the power block as a function of the usable direct normal irradiation for the saturated steam and superheated steam power plant for different operation modes (sliding pressure, modified sliding pressure and fixed pressure mode). 


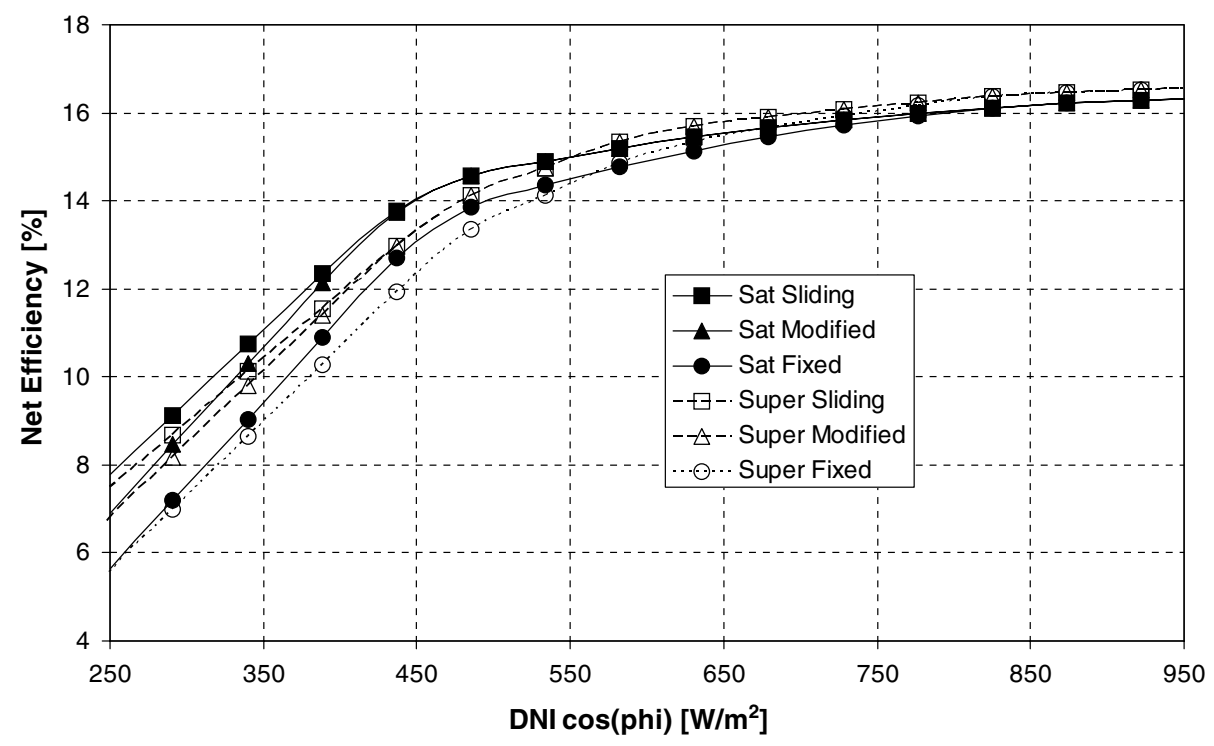

Fig. 10. Net efficiency of the solar thermal power plant as a function of the usable direct normal irradiation for the saturated steam and superheated steam power plant for different operation modes (sliding pressure, modified sliding pressure and fixed pressure mode).

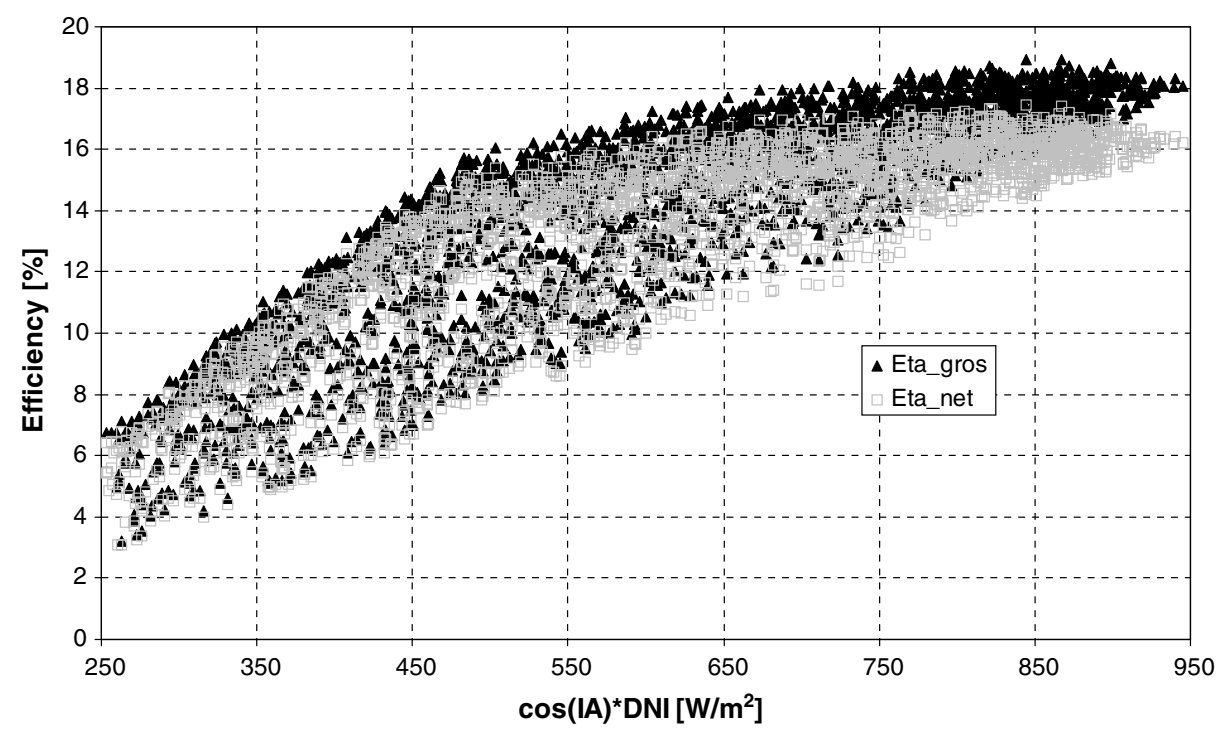

Fig. 11. Net and gross efficiency of the fixed pressure saturated steam process as a function of the product of DNI and the cosine of the incidence angle. Different efficiency values for identical DNI values are caused by different ambient temperatures and incidence angles.

that the saturated steam option is an interesting option for small size DSG solar thermal power plants.

Taking into consideration the offers available, the price for a superheated steam power block is roughly 1.5 million $€$, while the price considered for the saturated steam option is roughly 2.1 million $€$. The cost of the other power block compo- nents (deaerator, auxiliary pumps, piping and fittings) is very similar for both options and, therefore, the cost difference between both options related to the power block is 0.6 million $€$. As far as the solar field is concerned, the superheated steam option requires some items that are not needed in the saturated steam solar field. These items are 
Table 3

Results of the yearly calculation

\begin{tabular}{|c|c|c|c|c|c|c|}
\hline & \multicolumn{3}{|c|}{ Saturated steam } & \multicolumn{3}{|c|}{ Superheated steam } \\
\hline & SP & MSP & FP & $\mathrm{SP}$ & MSP & FP \\
\hline Max net efficiency [\%] & 17.5 & 17.5 & 17.5 & 17.6 & 17.6 & 17.6 \\
\hline Mean net efficiency $[\%]$ & 13.7 & 13.5 & 13.1 & 13.4 & 13.2 & 12.9 \\
\hline Net electricity prod. [MWh/a] & 10467 & 10434 & 10174 & 10033 & 9995 & 9738 \\
\hline Full load hours $[\mathrm{h}]$ & 1930 & 1923 & 1876 & 1849 & 1842 & 1795 \\
\hline
\end{tabular}

$\mathrm{SP}=$ Sliding pressure, $\mathrm{MSP}=$ modified sliding pressure, $\mathrm{FP}=$ fixed pressure.

- the water/steam separators and associated equipment (solenoid valve, non-return valve, piping and fittings) between the evaporating and superheating sections.

- the water injectors and associated equipment (piping, fittings, control valve and temperature sensor) used to control the steam temperature.

The number of parabolic trough collectors required for the saturated steam solar field of the DSG power plant considered in this study is 72 , while only 70 collectors are needed for the superheated steam option. The larger solar field compensates for the lower design efficiency of the saturated steam option. The differences between the solar fields of the two options considered are listed in Table 4, together with the number of units and the cost associated to every item. Costs are marked with "+" when the relevant item only exists in the superheated steam option, while the "_" sign is used for the items required in the saturated steam option only.

Taking into account the cost difference of both the power block and the solar field, it is concluded that the initial investment required by the saturated steam option is $710700 €$ higher than that of the superheated steam option, resulting in a $5 \%$ higher capital investment.

\subsection{Operation and maintenance issues}

Industrial turbines for saturated steam are not designed for daily start-up and shut-down because this kind of operation would reduce the equipment lifetime considerably and require frequent revisions and costly maintenance. Manufacturers recommend operating the turbine at low load conditions overnight by means of a fossil-fired back-up boiler or thermal energy storage. Therefore, the use of saturated steam turbines in a solar plant demands the implementation of costly maintenance procedures to assure a quality performance and durability. However, the extra maintenance costs required by a saturated steam turbine can not be quantified in general since service conditions imposed by every manufacturer are different. This can be done only on a case by case basis. What can be clearly stated is that the O\&M cost of a saturated steam turbine is higher.

Concerning operation requirements, saturated steam turbines seems to be less flexible than superheated steam ones, because great changes in the steam parameters can have a more dramatic effect. Nevertheless, the water/steam separator at the interface between the solar field and steam turbine has some benefits. If the volume of this separator is properly designed, it can also act as thermal energy storage if the turbine is operated with sliding pressure. The amount of saturated water and steam inside this vessel can feed the turbine with saturated steam at sliding pressure for a few minutes, thus overcoming short cloud transients. This is a very important advantage of the saturated steam option.

In summary, when O\&M issues are considered, DSG solar power plants with saturated steam have advantages and disadvantages when compared to the superheated steam option. However, an economic assessment of these advantages and disad-

Table 4

Economic comparison of saturated and superheated steam DSG solar fields

\begin{tabular}{llrr}
\hline Item & Units & Unit cost $(€)$ & Total cost $(€)$ \\
\hline Middle water/steam separator and associated equipment & 7 & 10500 & +73500 \\
Water injector and associated equipment & 7 & 5000 & +35000 \\
$548 \mathrm{~m}^{2}$ parabolic trough solar collectors (extra) & 2 & 109600 & -219200 \\
& & Total: & -110700 \\
\hline
\end{tabular}


vantages is still unfeasible due to the lack of experience with commercial DSG power plants. Though a theoretical study could be performed, the uncertainties resulting from a lack of experience would limit the accuracy of results obtained.

\section{Conclusion}

According to the investigation performed, the saturated steam option has a $4 \%$ higher annual net electricity production of the power plant. On the other hand, for the plant size analysed, the initial investment required by the saturated steam option is of about $5 \%$ higher than that of the superheated steam option. Though its maintenance cost is higher, the saturated steam option requires a less complex solar field and the water/steam separator located at the power block inlet can act as a thermal energy storage device. This configuration can feed the steam turbine with saturated steam at sliding pressure for few minutes, thus overcoming short cloudy periods. A further advantage of the saturated steam option is the possibility to use simpler collector options that are able to operate with a good efficiency at $260-300{ }^{\circ} \mathrm{C}$.

Due to the lack of experience with commercial DSG plants, a complete economic and technical assessment of both options, including all the aspects such as yearly performance, initial investment, operation and maintenance, is still unfeasible until the first DSG solar power plants are installed and deliver more accurate information. Therefore, the results presented should be regarded as preliminary, but nevertheless, the saturated steam DSG plant seems to be an interesting option for near term application in the lower capacity range.

\section{References}

Eck, M., Zarza, E., Eickhoff, M., Rheinländer, J., Valenzuela, L., 2003. Applied research concerning the direct steam generation in parabolic troughs'. Solar Energy 74 (4), 341-351.

Osuna, R., Fernandez, V., Romero, S., Romero, M., Sanchez, M. 2004. PS10: A 11.0-MW solar tower power plant with saturated steam receiver, In: Proceedings of the 12th Solar PACES International Symposium on Concentrated Solar Power and Chemical Energy Technologies, Oaxaca (México) October 6-8.

Ragwitz, M., Huber, C., 2005. Feed-In Systems in Germany and Spain and a Comparison, Report of the Fraunhofer Institut für Systemtechnik und Innovationsforschung (ISI), Breslauer Str. 48, 76139 Karlsruhe, Germany.

Zarza, E., Gonzales, L., Rojas, M.E., Caballero, J.M., Rueda, F. 2004. Conceptual design of a $5 \mathrm{MW}$ direct steam generation system, In: 12th Solar PACES international symposium, Oaxaca (México) October 6-8. 